\title{
Attitudes of Physicians towards Different Types of Euthanasia in Kuwait
}

\author{
Shaikhah Abohaimed ${ }^{a}$ Basma Matar ${ }^{a}$ Hussain Al-Shimalia Khalid Al-Thalji ${ }^{a}$ \\ Omar Al-Othman ${ }^{a}$ Yasmin Zurba ${ }^{a}$ Nasra Shah $^{\mathrm{b}}$ \\ ${ }^{a}$ Faculty of Medicine, Kuwait University, Jabriya, Kuwait; ${ }^{b}$ Department of Community Medicine, Faculty of Medicine, \\ Kuwait University, Jabriya, Kuwait
}

\section{Significance of the Study}

- This cross sectional study aimed to address the taboo topic of euthanasia in Kuwait. $44 \%$ of physicians reported the need for legalization of euthanasia and compared to a similar study published in Medical Principles and Practice in 2000, approval for passive euthanasia increased by $10 \%$. These results demand the attention of Ministry of Health, to discuss euthanasia and the need for clear guidelines and protocols.

\section{Keywords}

Mercy killing $\cdot$ End of life $\cdot$ Assisted suicide $\cdot$ Death

\section{Abstract}

Objective: Although in recent years the world has witnessed great advances in the medical field, much ambiguity still surrounds the issue of euthanasia and physician-assisted suicide, with increasingly favorable attitudes among physicians around the world. In our study, we aimed to assess the attitudes of physicians in Kuwait towards different types of euthanasia and examine whether physicians' frequent encounters with terminally ill patients were associated with their approval. Subjects and Methods: We conducted a crosssectional study on 464 physicians employed in government hospitals ( 6 general and 3 specialty hospitals). A self-administered questionnaire adapted from previous studies was used. Results: Of the physicians in our study, 43.9\% reported that the Ministry of Health should legalize euthanasia under certain restricted conditions. In addition, $29.1 \%$ of our population was willing to perform euthanasia. After controlling for several characteristics in logistic regression analysis, approval of passive euthanasia was significantly associated with the following 2 factors: frequent exposure to terminally ill patients ( $A O R=2.45$ ) and obtention of the basic medical degree from Asia (AOR = 4.36) or North America/Europe (AOR $=3.24$ ) compared to Kuwait. Male gender was significantly associated with willingness to perform euthanasia. Religion was the major reason for opposing euthanasia. Conclusion: The attitudes of physicians towards euthanasia are diverse, and therefore the Ministry of Health should provide guidelines for physicians dealing with situations where patients or their families request euthanasia.

$$
\begin{aligned}
& \text { () } 2019 \text { The Author(s) } \\
& \text { Published by S. Karger AG, Basel }
\end{aligned}
$$

\section{Introduction}

Much ambiguity still surrounds the issue of euthanasia and physician-assisted suicide, with its ethical, legal, and social ramifications. This is compounded by a shift in the attitudes of physicians towards this practice over the

\begin{tabular}{ll}
\hline KARGER & $\begin{array}{l}\text { ( } 2019 \text { The Author(s) } \\
\text { Published by S. Karger AG, Basel }\end{array}$ \\
E-Mail karger@karger.com & $\begin{array}{l}\text { This is an Open Access article licensed under the Creative Commons } \\
\text { Attribution-NonCommercial-4.0 International License (CC BY-NC) } \\
\text { (http://www.karger.com/Services/OpenAccessLicense), applicable to } \\
\text { the online version of the article only. Usage and distribution for } \\
\text { commercial purposes requires written permission. }\end{array}$
\end{tabular}

Shaikhah Salah Abohaimed

PO Box 23845

Safat 13099 (Kuwait)

E-Mail sabohaimed@gmail.com 
years. For example, according to Louhiala et al. [1], in Finland, physicians' support of euthanasia increased from $29 \%$ in 2003 to $46 \%$ in 2013. Attitudes among physicians in Kuwait are equally varied due to the diversity among physicians. Kuwait hosts doctors from countries such as Egypt, Syria, Lebanon, India, and Pakistan, as well as Kuwaiti nationals. This diversity is amplified by the myriad of religious beliefs among doctors in Kuwait, the majority being Muslim, followed by Christians and Hindus, as well as atheists.

There are 4 main types of euthanasia, i.e., active, passive, indirect, and physician-assisted suicide. Active euthanasia involves "the direct administration of a lethal substance to the patient by another party with merciful intent" [2]. Passive euthanasia is "withholding or withdrawing of life-sustaining treatment either at the request of the patient or when prolonging life is considered futile." Indirect euthanasia refers to the prescription of painkillers that may be fatal in an attempt to relieve suffering. Physician-assisted suicide refers to a medical professional aiding a patient in terminating their life upon the patient's request [3].

Although euthanasia is illegal in most countries, a few like The Netherlands, Belgium, and Luxembourg have legalized it under certain conditions [4]. A few states in the USA, including Oregon, Washington, Vermont, and Montana, have also permitted it [3]. In Kuwait, no specific law exists pertaining to euthanasia; however, the legal view may be inferred from article 149/4 of Kuwaiti criminal law that forbids murder, or ending a person's life. Moreover, euthanasia is forbidden under Islamic teachings [5].

Physician's views on euthanasia are an important element in the implementation of this practice. Their views may be influenced by many factors, including religion, the country where the physician is practicing medicine, or the physician's subspecialties within the medical field. Disapproval of euthanasia has been reported to be higher among those with strong religious beliefs. For example, in Catholicism, conservative Protestantism, and Islam, physician-assisted suicide and euthanasia are strictly prohibited, for the individual is believed to be "neither the author of his or her own life nor the arbiter of his or her own death." On the other hand, secular cultures support an individual's right to make his or her own decisions regarding life and death [4].

Various studies around the world have addressed the issue of euthanasia. In Greece, although $48 \%$ of physicians favored the legalization of euthanasia, only a small percentage stated that they would perform it, especially physician-assisted suicide [2]. In fact, physicians in Finland showed an increase in favorability toward administration of a possibly lethal dose of morphine to a cancer patient in 2015 as compared to 1999 [6]. In Japan, one fifth of physicians approved of voluntary euthanasia, although criminal law does not permit either assisted suicide or active voluntary euthanasia [7]. In contrast, a Malaysian study reported that $87 \%$ of physicians believed that patients did not have the right to make their own end-of-life decisions regardless of their condition; they also disapproved of physician-assisted suicide [3]. In the year 2000 a study in Kuwait demonstrated that only 19.9\% of physicians agreed with the notion that the Ministry of Health should approve euthanasia under certain restricted conditions [5].

Multiple studies have also reported on differences in approval among medical specialties. One such study found that geriatricians and oncologists in several European countries were less supportive of euthanasia compared to other specialties. Similarly, palliative doctors in France had less favorable opinions towards euthanasia than general physicians and neurologists, suggesting that more frequent encounters with terminally ill patients may lead to greater resistance to euthanasia [8].

Medical advances in Kuwait are likely to have lengthened the survival of terminally and chronically ill patients. The average life expectancy at birth stands at 79.4 years among both Kuwaitis and non-Kuwaitis, which is similar to the averages in several developed countries [9]. On the other hand, cancer cases among the Kuwaiti population have significantly increased over the last 4 decades [10]. For example, cancer rates among males increased from 89 cases per 100,000 individuals between 1974 and 1984 to 129 cases in 2013. Therefore, issues regarding prolongation of life even when the quality of life is compromised have become more common. However, decisions relating to euthanasia are often controversial, involving many different considerations. There is a pressing need for clear guidelines regulating the approach to the terminally ill. Our study was motivated by the absence of such guidelines in the context of rapid changes in health care possibilities that may generally prolong life.

The specific objectives of our study were: (1) to assess the attitudes of physicians in Kuwait toward different types of euthanasia and how such attitudes are associated with sociodemographic, cultural, and religious factors and (2) to examine whether regular encounters of physicians with terminally ill patients were associated with their approval of euthanasia. 


\section{Methods}

\section{Study Design}

We conducted a cross-sectional study on euthanasia in the period between December 27, 2015, and January 14, 2016. A survey was distributed to physicians in all 6 general hospitals and 3 specialty hospitals. The 3 specialty hospitals were selected on the basis of the expected exposure of physicians to terminally ill patients. Intensive care unit physicians, neurologists, neurosurgeons, physicians in the Kuwait Cancer Center (KCC(, and physicians in the National Bank of Kuwait (NBK) Hospital (for hematological malignancies) were considered to be relatively more exposed to terminally ill patients. We considered general surgeons and physicians in the internal medicine departments to be less exposed to terminally ill patients. All participants voluntarily completed the questionnaire and were assured about the anonymity of their identity.

\section{Ethical Approval}

The HSC (Health Sciences Center) Ethics Committee for Undergraduate Students' Research approved this research.

\section{Questionnaire}

Self-administered questionnaires with 27 structured questions were distributed to a total of 503 physicians; 464 of them returned completed questionnaires, yielding a response rate of $92.25 \%$. The questionnaire consisted of 2 main sections. The first section inquired about the demographic and background characteristics of the physicians. The second section included questions regarding the opinions and attitudes of physicians toward different types of euthanasia. The questionnaire was mostly based on the ones used in previous studies by Baume and O'Mally [11] and Askar et al. [5]. Also, our questionnaire asked about the possibility of and support for legalization of euthanasia, as was done by Seale [8]. The questionnaire was pretested on 12 medical doctors in the Faculty of Medicine of Kuwait University and its teaching hospital, and a few modifications were made accordingly.

Statistical analysis was performed using the SPSS statistical package version 23. Associations between categorical variables were tested using Pearson's $\mathrm{X}^{2}$ test and $\mathrm{X}^{2}$ for linear trend. Logistic regression was used to adjust certain associations for other variables. $p<0.05$ was considered statistically significant.

\section{Results}

\section{Sociodemographic Characteristics}

The characteristics of the physicians are shown in Table 1 . The total number of physicians enrolled into our study was 464 . Their mean age was $36.3 \pm 9.85$ years and $74.2 \%$ were male. In terms of nationality, $44.0 \%$ were $\mathrm{Ku}-$ waiti, $46.8 \%$ were non-Kuwaiti Arabs, and 9.3\% were non-Kuwaiti non-Arabs. A large majority (91.4\%) was Muslim, while the rest were Christian or of other religions. The majority (48.4\%) of the physicians were internists. Arab countries were the most common location for completion of the basic medical degree. Most participants
Table 1. Characteristics of the study population

\begin{tabular}{|c|c|}
\hline Characteristic & Value \\
\hline \multicolumn{2}{|l|}{ Gender } \\
\hline Male & $342(74.2)$ \\
\hline Female & $119(25.8)$ \\
\hline \multicolumn{2}{|l|}{ Age (years) } \\
\hline 30 or younger & $230(50.8)$ \\
\hline $31-39$ & $149(32.9)$ \\
\hline 40 or older & $74(16.3)$ \\
\hline Mean $( \pm \mathrm{SD})$ & $36.3 \pm 9.85$ \\
\hline \multicolumn{2}{|l|}{ Nationality } \\
\hline Kuwaiti & $204(44.0)$ \\
\hline Non-Kuwaiti Arab & $217(46.8)$ \\
\hline Non-Kuwait non-Arab & $43(9.3)$ \\
\hline \multicolumn{2}{|l|}{ Time in Kuwait (years) } \\
\hline$<5$ & $119(45.8)$ \\
\hline $5-10$ & $68(26.2)$ \\
\hline$>10$ & $73(28.1)$ \\
\hline \multicolumn{2}{|l|}{ Religion } \\
\hline Muslim & $424(91.4)$ \\
\hline Christian & $22(4.7)$ \\
\hline Other & $18(3.9)$ \\
\hline \multicolumn{2}{|l|}{ Rank } \\
\hline Trainee & $61(13.1)$ \\
\hline Assistant registrar & $69(14.9)$ \\
\hline Registrar & $162(34.9)$ \\
\hline Senior registrar & $81(17.5)$ \\
\hline Specialist/consultant & $91(19.6)$ \\
\hline \multicolumn{2}{|l|}{ Specialty } \\
\hline Internal medicine & $224(48.4)$ \\
\hline Surgery & $131(28.3)$ \\
\hline Oncology & $41(8.9)$ \\
\hline ICU/anesthesia & $67(14.5)$ \\
\hline \multicolumn{2}{|c|}{$\begin{array}{l}\text { Place were basic medical degree was } \\
\text { obtained }\end{array}$} \\
\hline Kuwait & $110(23.8)$ \\
\hline Arab country & $243(52.5)$ \\
\hline Asian country & $25(5.4)$ \\
\hline Europe and North America & $85(18.4)$ \\
\hline \multicolumn{2}{|l|}{ Holder of a postgraduate degree } \\
\hline Yes & $377(81.4)$ \\
\hline No & $86(18.6)$ \\
\hline \multicolumn{2}{|c|}{$\begin{array}{l}\text { Place where postgraduate degree was } \\
\text { obtained }\end{array}$} \\
\hline Kuwait & $106(28.3)$ \\
\hline Arab & $182(48.5)$ \\
\hline Asian country & $22(5.9)$ \\
\hline Europe and North America & $65(17.3)$ \\
\hline
\end{tabular}

Values are presented as numbers (\%) unless otherwise stated. The total number of patients was 464 . The numbers may not add up to the total due to some missing data. 


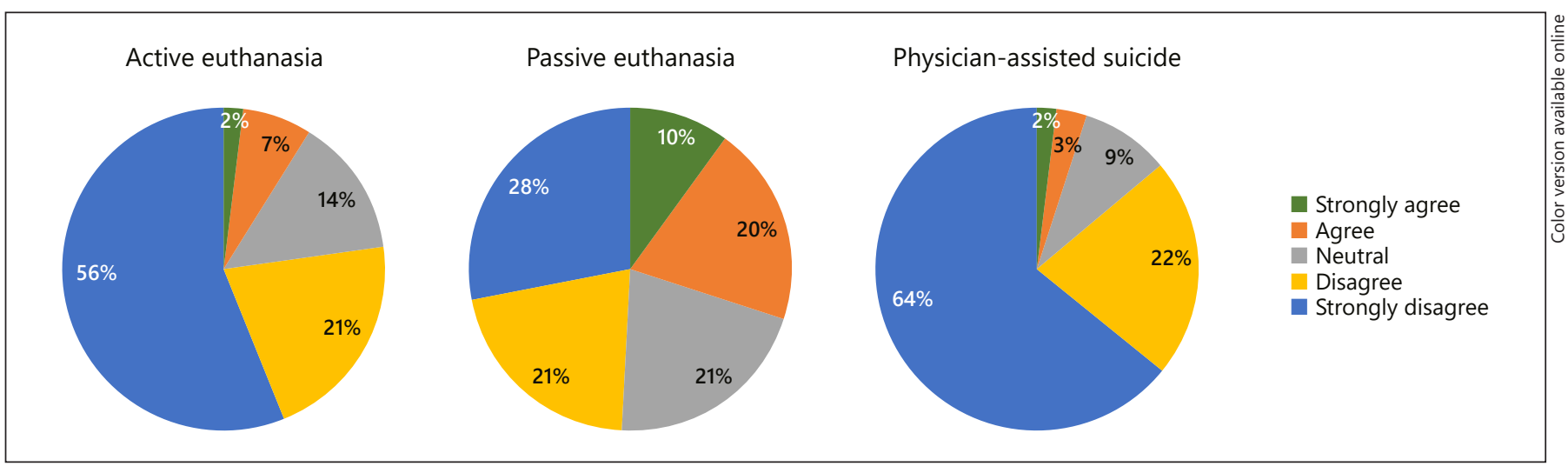

Fig. 1. Physicians' attitudes towards different types of euthanasia.

had postgraduate training (81.4\%), with almost half of them (48.5\%) completing their training in an Arab country.

Physician's Attitudes towards Euthanasia. About $11.3 \%$ of the physicians stated that they had considered taking steps to bring about a patient's death. The majority of the physicians in our sample (82.2\%) agreed that the primary objective when treating terminally ill patients is comfort rather than prolongation of life. A substantially large percentage (43.9\%) stated that euthanasia should be legalized in Kuwait under restricted conditions. When asked whether they would request euthanasia if they were terminally ill, $31.1 \%$ stated that they would do so. In addition, $28.9 \%$ of the physicians who approved of any type of euthanasia reported that they were willing to perform it themselves.

Figure 1 shows the opinions of physicians toward different types of euthanasia. Less than $10 \%$ of the physicians approved or strongly approved of active euthanasia, while the majority (77\%) disapproved or strongly disapproved. Passive euthanasia had the highest approval rate, i.e., 30\%; however, half of the physicians disapproved/ strongly disapproved of passive euthanasia. Only $5 \%$ stated that they approved/strongly approved of physicianassisted suicide, with $86 \%$ of them stating that they disapproved/strongly disapproved of this type of euthanasia.

Table 2 shows the association between physician's approval of passive euthanasia and their sociodemographic and other characteristics. Multiple factors were significantly associated with physicians' approval of passive euthanasia. A larger percentage of junior physicians approved of euthanasia, i.e., $44.1 \%$ of assistant registrars compared to $26.4 \%$ of specialists/consultants $(p=0.023)$. A larger percentage of physicians with less than 5 years of experience approved of passive euthanasia compared to physicians with more than 15 years of experience (i.e., 37.2 and $22.4 \%$, respectively; $p=0.039$ ). The same pattern was evident in the attitude towards euthanasia according to physician ranking. Regarding the place of basic medical training $(p=<0.001)$ and postgraduate training $(p=$ 0.001 ), a significantly larger percentage of physicians who trained in Asian countries or Europe/North America approved of passive euthanasia compared to physicians who trained in Kuwait or Arab countries. Frequent exposure to terminally ill patients among physicians was strongly associated with approval of passive euthanasia (35.0\%) versus less frequent or no exposure (21.3\%) $(p=0.001)$.

Approval of passive euthanasia was analyzed further by using logistic regression to adjust for the effect of confounders. Table 3 shows the results of this analysis. Two factors were found to have a significant association with physicians' approval of passive euthanasia. In comparison to physicians who completed their basic medical training in Kuwait, physicians who completed their basic medical training in an Asian country were more likely to approve of passive euthanasia $(\mathrm{AOR}=4.36$; $95 \%$ CI 1.29 $14.71 ; p=0.018$ ). Also, physicians who completed their basic medical training in Europe/North America reported a higher approval of passive euthanasia $(\mathrm{AOR}=3.24$; $95 \%$ CI $1.62-6.44 ; p=0.001)$. In terms of the exposure of physicians to terminally ill patients, frequent exposure was significantly associated with a higher approval (AOR $=2.45 ; 95 \%$ CI 1.48-4.05; $p=<0.001)$.

When asked about the reason for their disapproval, more than one reason was identified; $69.0 \%$ reported disapproval for religious reasons, $61.6 \%$ disapproved for personal/ethical reasons, and $17.7 \%$ adhered to society's disapproval. 
Table 2. Physicians' attitudes towards passive euthanasia according to sociodemographic characteristics

\begin{tabular}{|c|c|c|c|c|c|}
\hline & \multicolumn{4}{|c|}{ Passive euthanasia } & \multirow[t]{3}{*}{$p$ value $^{\mathrm{a}}$} \\
\hline & \multicolumn{2}{|c|}{ approve } & \multicolumn{2}{|c|}{ neutral/disapprove } & \\
\hline & $n$ & $\%$ & $n$ & $\%$ & \\
\hline Total & 134 & 29.1 & 327 & 70.1 & \\
\hline \multicolumn{6}{|l|}{ Age (years) } \\
\hline 30 or younger & 53 & 34.6 & 100 & 65.4 & \multirow[t]{3}{*}{0.223} \\
\hline $31-39$ & 45 & 29.8 & 106 & 71.2 & \\
\hline 40 or older & 35 & 24.0 & 111 & 76.0 & \\
\hline \multicolumn{6}{|l|}{ Gender } \\
\hline Male & 104 & 30.6 & 236 & 69.4 & \multirow[t]{2}{*}{0.228} \\
\hline Female & 30 & 25.4 & 88 & 74.6 & \\
\hline \multicolumn{6}{|l|}{ Nationality } \\
\hline Kuwaiti & 67 & 33.2 & 135 & 66.8 & \multirow[t]{2}{*}{0.087} \\
\hline Non-Kuwaiti & 67 & 25.9 & 192 & 74.1 & \\
\hline \multicolumn{6}{|l|}{ Rank } \\
\hline Trainee & 20 & 33.3 & 40 & 66.7 & \multirow[t]{5}{*}{0.023} \\
\hline Assistant registrar & 30 & 44.1 & 38 & 55.9 & \\
\hline Registrar & 37 & 22.8 & 125 & 77.2 & \\
\hline Senior registrar & 23 & 28.8 & 57 & 71.2 & \\
\hline Specialist/consultant & 24 & 26.4 & 67 & 73.6 & \\
\hline \multicolumn{6}{|l|}{ Religion } \\
\hline Muslim & 117 & 27.8 & 304 & 72.2 & \multirow[t]{3}{*}{0.094} \\
\hline Christian & 8 & 36.4 & 14 & 63.6 & \\
\hline Other & 9 & 50.0 & 9 & 50.0 & \\
\hline \multicolumn{6}{|c|}{ Place where basic degree was obtained } \\
\hline Kuwait & 26 & 23.9 & 83 & 76.1 & \multirow[t]{4}{*}{$<0.001$} \\
\hline Arab country & 55 & 22.7 & 187 & 77.3 & \\
\hline Asian country & 12 & 48.0 & 13 & 52.0 & \\
\hline Europe and North America & 40 & 47.6 & 44 & 52.4 & \\
\hline \multicolumn{6}{|c|}{ Place where postgraduate degree was obtained } \\
\hline Kuwait & 34 & 32.7 & 70 & 67.3 & \multirow[t]{4}{*}{0.001} \\
\hline Arab country & 33 & 18.2 & 148 & 81.8 & \\
\hline Asian country & 10 & 45.5 & 12 & 54.5 & \\
\hline Europe and North America & 25 & 38.5 & 40 & 61.5 & \\
\hline \multicolumn{6}{|l|}{ Specialty } \\
\hline Internal medicine & 69 & 30.7 & 156 & 69.3 & \multirow[t]{4}{*}{0.478} \\
\hline Surgery & 31 & 24.6 & 95 & 75.4 & \\
\hline Oncology & 11 & 26.8 & 30 & 73.2 & \\
\hline ICU/anesthesia & 23 & 34.3 & 44 & 65.7 & \\
\hline \multicolumn{6}{|l|}{ Exposure to terminally ill patients } \\
\hline Less frequent & 43 & 21.3 & 159 & 78.7 & \multirow[t]{2}{*}{0.001} \\
\hline Frequent & 90 & 35.0 & 167 & 65.0 & \\
\hline
\end{tabular}

The numbers may not add up to the total due to some missing data. ${ }^{a}$ Generated using Pearson's $\chi^{2}$ test.

The knowledge and attitudes of physicians about euthanasia were compared between those who reported that they had frequently treated terminally ill patients and those who had not (Table 4). In general, we found that the former group reported more positive attitudes towards several questions about euthanasia than the latter. When asked whether comfort was the primary objective rather than prolongation of life, $86.2 \%$ of those who frequently treated terminally ill patients agreed or strongly agreed versus $77.4 \%$ of those who did not frequently deal with terminally ill patients $(p=0.001)$. Attitudes towards legalization of euthanasia were more positive (48.6\%) among those who frequently treated terminally ill patients, compared to those who did not $(37.9 \%)(p=0.022)$. Further- 
more, $36.3 \%$ of those who frequently treated terminally ill patients said that they would request euthanasia if they were terminally ill, compared to $24.4 \%$ of those who did $\operatorname{not}(p=0.006)$. Finally, when asked if it is appropriate to give pain medications to relieve suffering even if they hasten the patient's death, $28.6 \%$ of those frequently exposed to terminally ill patients strongly agreed, compared to $16.3 \%$ agreement among those less exposed $(p=0.002)$.

\section{Willingness to Perform Euthanasia}

In terms of the association between the physician's willingness to perform euthanasia and their sociodemographic and other characteristics, 3 factors were found to be statistically significant (data not shown). More male physicians (31.7\%) than female physicians $(20.5 \%)$ ( $p=$ 0.043 ) were willing to perform euthanasia. A larger percentage of younger physicians aged less than 30 years $(37.8 \%)$ said that they would consider performing euthanasia, compared to $26.9 \%$ among physicians aged $31-39$ years and $23.4 \%$ among those aged 40 years and older $(p=0.016)$. Regarding the place of postgraduate training, physicians who trained in Arab countries (19.6\%) were markedly the least willing to perform euthanasia, compared to physicians who trained in Europe/North America (35.4\%), Asian countries (35.0\%), or Kuwait (33.8\%) $(p=0.042)$.

\section{Discussion}

This cross-sectional study assessed the attitudes of 464 physicians in Kuwait regarding different types of euthanasia in relation to several factors including sociodemographic, cultural, and religious characteristics and the frequency of physicians' encounters with terminally ill patients.

Euthanasia is legal in The Netherlands, Belgium, and the US states of Oregon and Washington, and discussions on legalization of this act are ongoing in many countries around the globe. In our study, we found that, although Kuwaiti law prohibits euthanasia, many physicians thought that the Ministry of Health should reconsider. About $29 \%$ of the physicians expressed favorable attitudes towards passive euthanasia, but a larger percentage (43.9\%) reported that the Ministry of Health should legalize euthanasia under certain restricted conditions. Moreover, $29.1 \%$ of our population was willing to perform euthanasia. Globally, a change in attitudes towards euthanasia has been accompanied by concerns about the difficulty in defining and enforcing the guidelines that
Table 3. Logistic regression of physicians' attitude towards passive euthanasia according to sociodemographic characteristics

\begin{tabular}{llll}
\hline Variable $^{\mathrm{a}}$ & $\mathrm{AOR}^{\mathrm{b}}$ & $95 \% \mathrm{CI}^{\mathrm{c}}$ & $p$ value \\
\hline Place where basic degree was obtained & & \\
Kuwait (reference) & 1.00 & & \\
Arab country & 1.29 & $0.65-2.56$ & 0.476 \\
Asian country & 4.36 & $1.29-14.71$ & 0.018 \\
Europe and North America & 3.24 & $1.62-6.44$ & 0.001 \\
\hline Exposure to terminally ill patients & & & \\
Less frequent & 1.00 & & \\
Frequent & 2.45 & $1.48-4.05$ & $<0.001$ \\
\hline
\end{tabular}

a Physicians who responded that they "strongly agree" or "agree" were grouped into one variable and assigned the value 1; those who responded with "neutral", "disagree," or "strongly disagree" were grouped into one variable and assigned the value 0 . $\mathrm{b}$ Controling for age, gender, nationality, rank, years of experience, place where the basic medical degree was obtained, frequency of interaction with terminally ill patients, and postgraduate training. ${ }^{c}$ For the OR.

surround this issue. Thoughts about legalization also coincide with concerns about whether it is possible to keep the act under agreed restrictions; for example, euthanasia might start to seem like the easier option rather than prolongation of the life of a terminally ill patient [12]. This might lead us to the "slippery slope effect", an argument present in debates on euthanasia since the 1930s, in which lawyer Eugene Volokh [13] argued that legalization of euthanasia might lead to unwanted consequences. For example, it may result in a dangerous situation in which patients might feel like a burden on their families, and hence euthanasia would be an alternative to a prolonged hospital stay and suffering. This underlines the fact that guidelines on dealing with end-of-life decisions in $\mathrm{Ku}$ wait, that are not yet clearly set, should be devised with great care.

There was a wide range in attitudes towards the 3 types of euthanasia. About $29 \%$ of the physicians approved of passive euthanasia, compared to $8.7 \%$ who approved of active euthanasia and only $4.5 \%$ who approved of physician-assisted suicide. Similar findings were reported by Steinberg et al. [14], who found that $54 \%$ of physicians approved of passive euthanasia but only $35 \%$ approved of active euthanasia. A possible reason for the higher approval of passive euthanasia is the similarity between passive euthanasia and termination of life support in braindead patients, which is both legal and widely practiced. Another reason is that in passive euthanasia the physician is not directly responsible for the patient's death [5]. Fur- 
Table 4. Knowledge of and attitude toward euthanasia according to the frequency of exposure to terminally ill patients

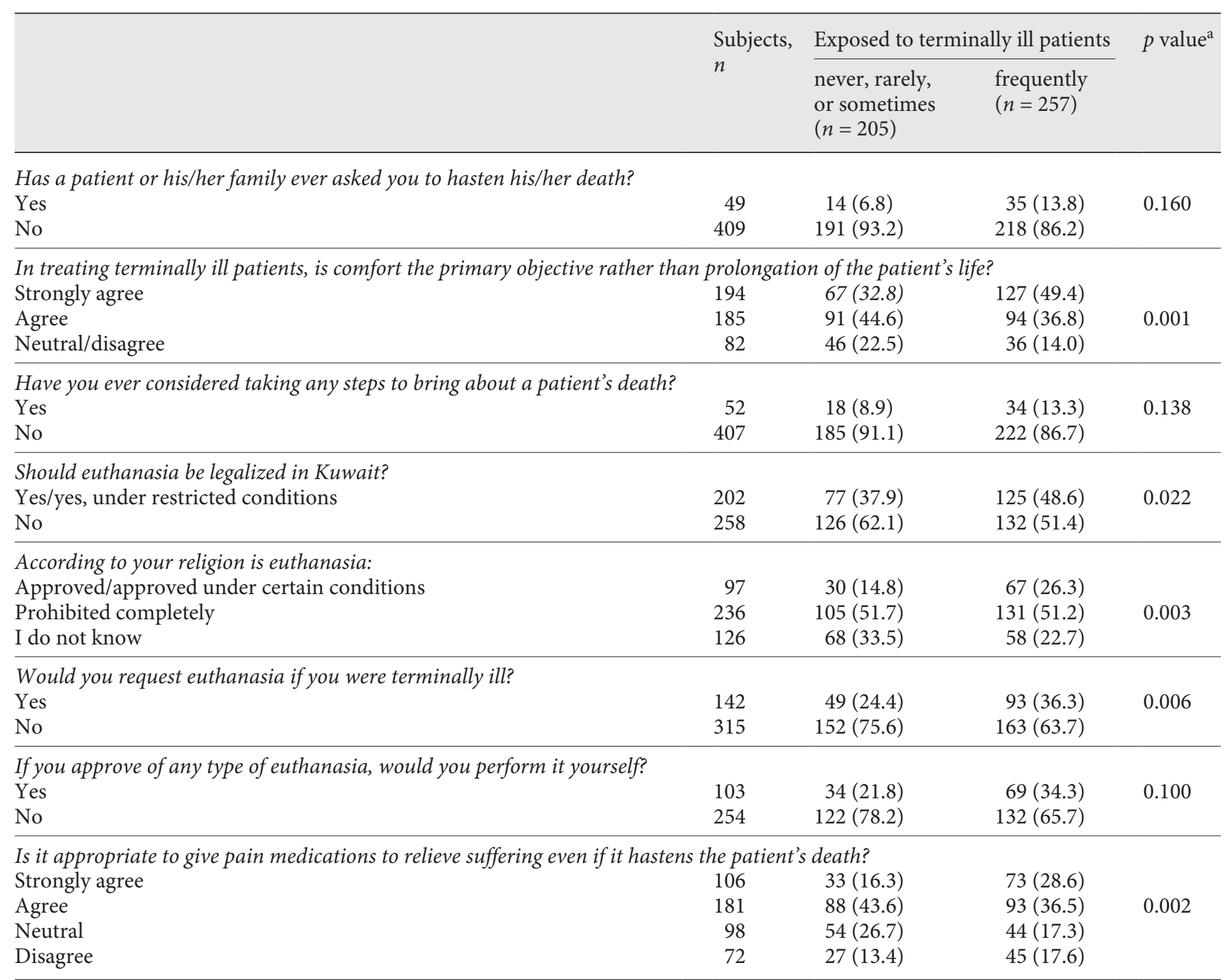

Values are presented as numbers (\%) unless otherwise stated. The numbers may not add up to the total due to some missing data. a Generated using Pearson's $\chi^{2}$ test.

thermore, Louhiala et al. [1] reported an increase in approval of euthanasia among Finnish physicians; however, possible causes of the changes could not be addressed due to the cross-sectional nature of the study. The observed rise in approval among Kuwaiti physicians could be due to the fact that life expectancy is on the rise and patients can be kept alive with advanced life support measures.

Compared to a study conducted on physicians in $\mathrm{Ku}-$ wait 15 years ago, an overall increase in the approval of all types of euthanasia was evident, especially with regard to passive euthanasia (i.e. approval increased from $19.7 \%$ in the previous study to $29.0 \%$ in our study) [5]. In fact,
$43.9 \%$ of the physicians agreed that the Ministry of Health should legalize euthanasia under certain restricted conditions, compared to $19.9 \%$ in the previous study.

A major determinant of support towards euthanasia is religion. According to Kamath et al. [15], in a study conducted in India, $76.9 \%$ of Muslims and $64.3 \%$ of Christians had unfavorable opinions regarding euthanasia, compared to $24.3 \%$ of those practicing Hinduism. Danyliv and O'Neill [16] also added that the support for legalization of euthanasia has dramatically increased over the past years, which corresponds to an increase in secularization in the British society. The opinion of the physi- 
cians in our study were similar. We found that only $32 \%$ of Muslims approved of euthanasia when given a scenario involving an elderly comatose patient; this was the lowest percentage, compared to $59.1 \%$ of Christians and $61.1 \%$ of those of other religions $(p=0.002)$. Additionally, $69.0 \%$ of the physicians in our study reported religion as their reason for disapproval towards euthanasia.

Attitudes towards euthanasia varied between male and female physicians. Although in our study gender was not found to be a statistically significant determinant of physicians' attitudes, a larger percentage of males compared to females consistently supported euthanasia on various questions that we asked. This finding is coherent with a study conducted by Levy et al. [17] in which male physicians showed a higher approval of different scenarios regarding euthanasia. When asked about their willingness to perform euthanasia, $31.7 \%$ of the males in our study were willing to perform euthanasia versus $20.5 \%$ of the female physicians $(p=0.043)$. One explanation for such a finding may be that women "are likely to make more 'emotional' and 'principled' decisions" [18]. Another possible reason for the more conservative attitude among female doctors is that women probably make more measured decisions.

A Finnish study reported that younger physicians were more likely to disapprove of euthanasia [19]. However, in our study younger physicians had more favorable opinions than older physicians, which is coherent with what Miccinesi et al. [20] and Gielen et al. [21] reported for several European countries. This could be attributed to the fact that older physicians are likely to have treated more terminally ill patients [21] and are more aware of treatment alternatives, making them less inclined toward ending a patient's life prematurely. In addition, it is possible that younger physicians are generally in better health and therefore think that euthanasia is preferable to the long-term endurance of pain or disease. Another explanation is that younger physicians are perhaps more tolerant of unconventional ideas, including the varying approaches to end-of-life care, such as euthanasia.

We found a significant difference in attitudes in terms of where the basic medical degree was earned. Physicians who graduated from universities in Europe, North America, and Asia tended to approve of euthanasia more than physicians who graduated from universities in Kuwait and Arab countries. For example, $47.6 \%$ of the physicians who graduated from Europe and America, and 48\% of those who obtained a basic medical degree from Asia, supported passive euthanasia, compared to 32.7 and $18.2 \%$ of those who graduated from universities in $\mathrm{Ku}$ - wait or an Arab country, respectively $(p<0.001)$. The country from which the basic medical degree was obtained also emerged as a significant variable in the logistic regression analysis of support for passive euthanasia, with an AOR for Europe/North America of 3.24 (95\% CI 1.626.44) and an AOR of 4.36 for Asia (95\% CI 1.29-14.71). A possible explanation for the above result may be that physicians who have a more positive attitude towards euthanasia are affected by the environment in which they were educated and trained, especially if it was in a country where euthanasia was a more acceptable practice.

Some studies have found that physicians such as oncologists, geriatricians, and ICU specialists, who frequently deal with terminally ill patients, were more opposed to euthanasia and physician-assisted suicide [7, 22]. In fact, oncologists in France were also less approving of the legalization of euthanasia [23]. However, in our study, physicians who reported that they were frequently exposed to terminally ill patients were more consistently supportive of euthanasia in terms of the various questions that were asked. For example, $35.0 \%$ of those who were frequently exposed to terminally ill patients approved of passive euthanasia versus $21.3 \%$ of those who were not $(p=0.001)$. When logistic regression analysis was performed, the AOR for approval of passive euthanasia among physicians frequently exposed to terminally ill patients was 2.45 times the odds of those who were less frequently exposed (95\% CI 1.48 - 4.05).

The major strength of our study lies in the fact that we included physicians from all 6 general hospitals in Kuwait as well as all oncology and palliative care center physicians, increasing the chances that our sample was adequately representative of physicians in the government sector. Some responses may suffer generally from selfreport bias.

\section{Conclusion}

The Kuwaiti medical community is in need of more studies and awareness regarding euthanasia and its types. About two fifths of the physicians supported the legalization of euthanasia under restricted conditions. Therefore, it is essential for the Ministry of Health and the medical community in Kuwait to address this issue and provide guidelines for physicians dealing with situations where the patient or his/her family requests euthanasia, but the physician does not have a protocol to follow. 


\section{References}

1 Louhiala P, Enkovaara $H$, Halila $H$, Pälve $H$, Vänskä J. Finnish physicians' attitudes towards active euthanasia have become more positive over the last 10 years. J Med Ethics. 2015 Apr;41(4):353-5.

2 Parpa E, Mystakidou K, Tsilika E, Sakkas P, Patiraki E, Pistevou-Gombaki K, et al. Attitudes of health care professionals, relatives of advanced cancer patients and public towards euthanasia and physician assisted suicide. Health Policy. 2010 Oct;97(2-3):160-5.

3 Rathor MY, Abdul Rani MF, Shahar MA, Jamalludin AR, Che Abdullah ST, Omar AM, et al. Attitudes toward euthanasia and related issues among physicians and patients in a multi-cultural society of Malaysia. J Family Med Prim Care. 2014 Jul;3(3):230-7.

4 Cohen J, Van Landeghem P, Carpentier N, Deliens L. Public acceptance of euthanasia in Europe: a survey study in 47 countries. Int J Public Health. 2014 Feb;59(1):143-56.

5 Askar A, Nakhi M, Al-Rashidi K, Al-Musabbahie BA, Shah NM. Physicians' attitudes towards euthanasia in Kuwait. Med Princ Pract. 2000;9(4):268-81.

6 Piili RP, Metsänoja R, Hinkka H, Kellokumpu-Lehtinen PI, Lehto Piili RP, Metsänoja R, Hinkka H, Kellokumpu-Lehtinen PI, Lehto JT. Changes in attitudes towards hastened death among Finnish physicians over the past sixteen years. BMC Med Ethics. 2018 May; 19(1):40.

7 Asai A, Ohnishi M, Nagata SK, Tanida N, Yamazaki Y. Doctors' and nurses' attitudes towards and experiences of voluntary euthanasia: survey of members of the Japanese Association of Palliative Medicine. J Med Ethics. 2001 Oct;27(5):324-30.
8 Seale C. Legalisation of euthanasia or physician-assisted suicide: survey of doctors' attitudes. Palliat Med. 2009 Apr;23(3):205-12.

9 Ministry of Health of Kuwait. The Annual Health Report. 51st ed. Kuwait City: Minostry of Health of Kuwait; 2014.

10 KUNA [Internet]. Cancer second cause of death in Kuwait [cited 2016 May 5]. Available from: http://news.kuwaittimes.net/website/ cancer-second-cause-death-kuwait/.

11 Baume P, O’Malley E. Euthanasia: attitudes and practices of medical practitioners. Med J Aust. 1994 Jul;161(2):137.

12 Battin MP, van der Heide A, Ganzini L, van der Wal G, Onwuteaka-Philipsen BD. Legal physician-assisted dying in Oregon and the Netherlands: evidence concerning the impact on patients in "vulnerable" groups. J Med Ethics. 2007 Oct;33(10):591-7.

13 Volokh E. Mechanisms of the slippery slope. Harv Law Rev. 2003 Feb;116(4):1057-8.

14 Steinberg MA, Najman JM, Cartwright CM, MacDonald SM, Williams GM. End-of-life decision-making: community and medical practitioners' perspectives. Med J Aust. 1997 Feb;166(3):131-5.

15 Kamath S, Bhate P, Mathew G, Sashidharan S, Daniel AB. Attitudes toward euthanasia among doctors in a tertiary care hospital in South India: a cross sectional study. Indian J Palliat Care. 2011 Sep;17(3):197-201.

16 Danyliv A, O’Neill C. Attitudes towards legalising physician provided euthanasia in Britain: the role of religion over time. Soc Sci Med. 2015 Mar;128:52-6.
17 Levy TB, Azar S, Huberfeld R, Siegel AM, Strous RD. Attitudes towards euthanasia and assisted suicide: a comparison between psychiatrists and other physicians. Bioethics. 2013 Sep;27(7):402-8.

18 Hinkka H, Kosunen E, Lammi EK, Metsänoja R, Puustelli A, Kellokumpu-Lehtinen P. Decision making in terminal care: a survey of finnish doctors' treatment decisions in end-of-life scenarios involving a terminal cancer and a terminal dementia patient. Palliat Med. 2002 May;16(3):195-204.

19 Ryynänen OP, Myllykangas M, Viren M, Heino $\mathrm{H}$. Attitudes towards euthanasia among physicians, nurses and the general public in Finland. Public Health. 2002 Nov;116(6): 322-31.

20 Miccinesi G, Fischer S, Paci E, OnwuteakaPhilipsen BD, Cartwright C, van der Heide A, et al.; EURELD consortium. Physicians' attitudes towards end-of-life decisions: a comparison between seven countries. Soc Sci Med. 2005 May;60(9):1961-74.

21 Gielen J, Van Den Branden S, Broeckaert B. Attitudes of European physicians toward euthanasia and physician-assisted suicide: a review of the recent literature. J Palliat Care. 2008;24(3):173-84.

22 Emanuel EJ. Euthanasia and physician-assisted suicide: a review of the empirical data from the United States. Arch Intern Med. 2002 Jan; 162(2):142-52.

23 Peretti-Watel P, Bendiane MK, Pegliasco H, Lapiana JM, Favre R, Galinier A, et al. Doctors' opinions on euthanasia, end of life care, and doctor-patient communication: telephone survey in France. BMJ. 2003 Sep; 327(7415):595-6. 